\title{
Beyond the Modernization Theory: Socio-Demographic Changes, Economic Structure and Forest Transition in a Multi-Dimensional Time-Series Analysis for
} Italy

\author{
Agostino Ferrara1, Luca Salvati2 ${ }^{*}$, Claudia Becagli3 ${ }^{3}$, Giada Bertini ${ }^{3}$ \\ ${ }^{1}$ Scuola di Scienze Agrarie, Forestali, Alimentari ed Ambientali, Università degli Studi della Basilicata, Potenza, \\ Italy \\ ${ }^{2}$ Consiglio per la Ricerca e la Sperimentazione in Agricoltura, Centro per lo Studio delle Relazioni Pianta-Suolo \\ (CRA-RPS), Rome, Italy \\ ${ }^{3}$ Consiglio per la Ricerca e la Sperimentazione in Agricoltura, Centro di Ricerca per la Selvicoltura (CRA-SEL), \\ Arezzo, Italy \\ Email: luca.salvati@entecra.it
}

Received 28 August 2014; revised 7 October 2014; accepted 20 October 2014

Copyright (C) 2014 by authors and Scientific Research Publishing Inc.

This work is licensed under the Creative Commons Attribution International License (CC BY).

http://creativecommons.org/licenses/by/4.0/

(c) (i) Open Access

\begin{abstract}
In the light of the modernization theory, the present paper proposes an empirical assessment of the population-economy-environment nexus in Italy by investigating the historical trends (18622009) in 58 variables describing five themes (environment, demography, education, trade, agriculture). Socioeconomic variables representing changes in population structure and demographic dynamics compared with indicators of forest expansion allowed verifying the temporal coherence between demographic and forest transitions at the country scale. The study develops an exploratory data analysis framework based on principal component analysis, hierarchical and non-hierarchical clustering and identifies four homogeneous time intervals $(1862-1899,1900-1930,1931-$ 1970, 1971-2009) in socioeconomic and environmental attributes. Different trends (positive linear, negative linear and non-linear) in the studied variables were identified through hierarchical clustering.
\end{abstract}

\section{Keywords}

Forest Expansion, Population Structure, Socioeconomic Dynamics, Exploratory Data Analysis, Italy

\footnotetext{
${ }^{*}$ Corresponding author.
}

How to cite this paper: Ferrara, A., Salvati, L., Becagli, C. and Bertini, G. (2014) Beyond the Modernization Theory: SocioDemographic Changes, Economic Structure and Forest Transition in a Multi-Dimensional Time-Series Analysis for Italy. Open Journal of Social Sciences, 2, 183-194. http://dx.doi.org/10.4236/iss.2014.211024 


\section{Introduction}

Modernization theory proposes a process-based explanation of the transformation from traditional or underdeveloped societies to modern societies. Modernization theory is concerned with economic growth within societies; agricultural mechanization, industrialization and the rapid shift towards services are ingredients in the process of economic growth [1]. The theory emerged in the 1950s as an explanation of how the industrial societies of North America and Western Europe developed and focused on the social, political, and cultural consequences of economic growth and the conditions that are important for industrialization and economic development to occur [2]. Modernization implies that societies develop in fairly predictable stages though which they become increasingly complex [3]. Development depends primarily on the importation of technology as well as a number of other political and social changes believed to come about as a result, including increased levels of education, the development of transport, communication and mass media, international trade, urbanization and the decline in importance of the extended family [4]. While traditional society is based on direct interaction between people living close to each other, modern societies stretch further and further across space and time using interactive media [5], symbolic means, English as the lingua franca and the Internet [6]. These changes are particularly evident when studying the long-term evolution of a country (or a region) based on a number of different social, cultural and economic indicators [7].

Important feedback mechanisms of the modernization theory are demographic and environmental transitions. The role of feedbacks, thresholds and synergies in the interaction of population dynamics and the environment are relatively well known with examples drawn from climate change, land-use, soil degradation, desertification, pollution and other global and regional issues. With the ecological consequences of increasing human population size being dynamic and nonlinear, the widely assumed notion that environmental degradation grows in proportion to population size is considered overly optimistic while feedbacks are demonstrated to trigger non-linear degradation trends [8]. The present study is aimed at exploring the complexity in the long-term population-environment nexus over a long time period in the light of the modernization theory. An original analysis of a large set of indicators representing five research themes (environment, demography, education, trade and agriculture) based on data mining techniques allowed us to investigate the changing socioeconomic context at the base of both demographic transition and forest transition.

Demographic transition (DT) refers to the transition from high birth and death rates to low birth and death rates as a country develops from a pre-industrial to an industrialized economic system with consequent societal and environmental changes [9]. The transition involves four stages. In stage one, pre-industrial society, death rates and birth rates are high and roughly in balance [10]. In stage two the death rates drop rapidly due to improvements in food supply and sanitation, which increase life spans and reduce disease. In stage three, birth rates fall due to access to contraception, increases in wages, urbanization, a reduction in subsistence agriculture, an increase in the status and education of women, a reduction in the value of children's work, a rise in parental investment in the education of children and other social changes [11]. During stage four low birth rates and low death rates were observed [12].

When linked to changes involving the local environment [13]-[15], forest transition (FT) indicates a process with divergent trends in forest cover (from decline to expansion of country forest areas and vice versa) depending on the socioeconomic conditions [16]-[19]. Results from case studies [20]-[27] demonstrate that changes from net deforestation to net reforestation depend on factors such as the level of industrialization, population dynamics (i.e. rural abandonment and urbanization), agricultural intensification, learning and education level, quality of policies and governance and increased environmental awareness [14] [28]-[30]. The FT theory has been proved to be a useful tool for understanding land-use changes and the evolution of environmental degradation [31] [32] and to prescribe policies that promote sustainable land management [33]-[35]. Based on these premises, it is clear that the interconnection between DT and FT is possibly relevant in developed countries when evaluated in the broad context of the modernization theory. It involves multiple dimensions that cannot be isolated and, instead, should be considered as synergic drivers of change. The present study contributes to this view by assessing long-term changes (1862-2009) in 58 indicators illustrating five themes that describe the multiple processes and waves of economic growth in Italy. The multiple aims of this study are 1) to clarify the empirical nexus among the investigated variables, 2) to classify years according to the dominant socioeconomic context and 3) to identify homogeneous time periods based on different modernization waves. 


\section{Methods}

\subsection{Study Area}

The investigated area covers Italy extending for $301,330 \mathrm{~km}^{2}$ whose territory is formed by nearly $23 \%$ lowland, $42 \%$ upland and the remaining $35 \%$ of land by mountainous areas. Italy is characterized by a north-south divide in environmental conditions (climate regimes, landscape, vegetation, soils and cropping systems) and socioeconomic variables (income, job market, demographic and socio-spatial structures). Italian land is actually administered by twenty regional authorities, more than 100 provinces and nearly 8100 local municipalities. All the variables collected at the national scale along the study period (1862-2009) refer to the related geographical boundaries [36].

\subsection{Statistical Indicators}

The present study is based on 58 indicators derived from a large set of homogeneous time-series annual data (1862-2009) made available at the country scale by the Italian National Institute of Statistics (ISTAT) along the entire investigated time window and collected and harmonized from various official data sources (e.g. national census of population, demographic register, forest and environmental statistics, economic statistics and social statistics). Indicators include 7 environmental and territorial variables, 12 demographic variables, 7 education variables, 8 trade variables and 24 agricultural variables (Table 1). The selected indicators are considered as reliable and homogeneous over time and provide a quite comprehensive picture of the socio-demographic changes observed on a time interval of 150 years in Italy with an annual time step.

Table 1. List of the variables used in the present study.

\begin{tabular}{|c|c|c|c|}
\hline Theme & Acronym & Indicator & Source \\
\hline \multirow[t]{7}{*}{$\begin{array}{l}\text { Environment and } \\
\text { territory }\end{array}$} & $\mathrm{FO} \%$ & Forest land (\% on total land) & Forest statistics \\
\hline & FOP & Per-capita forest area ( $\mathrm{m}^{2}$ per inhabitant) & Forest statistics \\
\hline & GRO & Population growth (per year \% rate) & Demographic statistics \\
\hline & POP & Resident population (logarithm) & Demographic statistics \\
\hline & PAR & Protected area (\% on total land) & Environmental statistics \\
\hline & RAI & Railway network (km/1000 inhabitants) & Economic statistics \\
\hline & URB & Population residing in urban centres (\% on total) & Demographic statistics \\
\hline \multirow[t]{12}{*}{ Demography } & SEX & Sex ratio (males vs females) & Demographic statistics \\
\hline & BIR & Birth rate (\% on total population) & Demographic statistics \\
\hline & DEA & Death rate (\% on total population) & Demographic statistics \\
\hline & MIG & Migration rate (\% on total population) & Demographic statistics \\
\hline & NAT & Natural children rate (\% on total births) & Demographic statistics \\
\hline & STI & Still birth rate (\% on total births) & Demographic statistics \\
\hline & BRI & Age difference between groom and bride (years) & Demographic statistics \\
\hline & MAR & Marriage rate (\% on total population) & Demographic statistics \\
\hline & SPO & Average age of the groom at the marriage (years) & Demographic statistics \\
\hline & AGE & Median age at death for males (years) & Demographic statistics \\
\hline & MER & Difference in female vs male median age (years) & Demographic statistics \\
\hline & DE0 & Death at age $0-4$ years (\% on total population) & Demographic statistics \\
\hline Education & TER & Third-level graduated (\% on total population) & University statistics \\
\hline
\end{tabular}




\section{Continued}

\begin{tabular}{|c|c|c|c|}
\hline & GRA & Second-level graduated (\% on total population) & School statistics \\
\hline & SCI & Enrolled at the university in science faculties (\%) & University statistics \\
\hline & MED & Enrolled at the university in medicine faculties (\%) & University statistics \\
\hline & AGR & Enrolled at the university in agrarian faculties (\%) & University statistics \\
\hline & ECO & Enrolled at the university in economy faculties (\%) & University statistics \\
\hline & LAW & Enrolled at the university in law faculties (\%) & University statistics \\
\hline \multirow[t]{24}{*}{ Agriculture } & WHP & Wheat production (per 1000 quintals) & Agricultural statistics \\
\hline & RYE & Rye production (per 1000 quintals) & Agricultural statistics \\
\hline & BAR & Barley production (per 1000 quintals) & Agricultural statistics \\
\hline & OAT & Oat production (per 1000 quintals) & Agricultural statistics \\
\hline & RIC & Rice production (per 1000 quintals) & Agricultural statistics \\
\hline & MAI & Maize production (per 1000 quintals) & Agricultural statistics \\
\hline & BRO & Broad bean production (per 1000 quintals) & Agricultural statistics \\
\hline & BEA & Bean production (per 1000 quintals) & Agricultural statistics \\
\hline & POT & Potatoes production (per 1000 quintals) & Agricultural statistics \\
\hline & TOB & Tobacco production (per 1000 quintals) & Agricultural statistics \\
\hline & GRA & Wine grapes production (per 1000 quintals) & Agricultural statistics \\
\hline & OLI & Olive production (per 1000 quintals) & Agricultural statistics \\
\hline & ORA & Orange production (per 1000 quintals) & Agricultural statistics \\
\hline & TAN & Tangerine and clementine production (per 1000 quintals) & Agricultural statistics \\
\hline & LEM & Lemon production (per 1000 quintals) & Agricultural statistics \\
\hline & $\mathrm{OTH}$ & Other agrumes' production (per 1000 quintals) & Agricultural statistics \\
\hline & ALM & Almond production (per 1000 quintals) & Agricultural statistics \\
\hline & HAZ & Hazel production (per 1000 quintals) & Agricultural statistics \\
\hline & CRO & Per capita agricultural production (quintals) & Agricultural statistics \\
\hline & CAT & Total density of cattle and buffaloes (animals) & Agricultural statistics \\
\hline & SHE & Total density of sheep and goats (animals) & Agricultural statistics \\
\hline & PIG & Total density of pigs (animals) & Agricultural statistics \\
\hline & HOR & Total density of horses (animals) & Agricultural statistics \\
\hline & EGG & Total number of eggs produced (per 1000 units) & Agricultural statistics \\
\hline \multirow[t]{8}{*}{ Trade } & IEU & Import from Europe (\% on total import) & Trade statistics \\
\hline & IAM & Import from north America (\% on total import) & Trade statistics \\
\hline & EEU & Export to Europe (\% on total import) & Trade statistics \\
\hline & EAM & Export to north America (\% on total export) & Trade statistics \\
\hline & DEP & Bank deposit amount/total loan amount & Economic statistics \\
\hline & OIL & Imported oil/imported carbon & Trade statistics \\
\hline & WHE & Wheat production/wheat import & National accounts \\
\hline & BAL & Total import/total export & Trade statistics \\
\hline
\end{tabular}




\subsection{Data Analysis}

The 58 indicators described in Section 2.2 were calculated for each year between 1862 and 2009 and subjected to a data mining framework incorporating Principal Component Analysis (PCA), hierarchical clustering (HC) and non-hierarchical k-means Clustering (NC). The PCA was run separately on the five research themes to identify correlations among the studied indicators and their evolution over time in the 147 years studied. Components with eigenvalues $>2$ were extracted and five separate plots for component loadings (the 58 variables) were analyzed. A HC based on Euclidean distance with Ward's agglomeration algorithm was developed to identify similarities in the temporal distribution of the 58 indicators taken together. This analysis clustered variables according to their time trend (e.g. linear positive, linear negative, non-linear, stable). A NC (based on the Cubic Clustering Criterion to identify the optimal partition number) was used to classify the examined years into a restricted number of homogeneous groups. A Fisher-Snedecor statistic was carried out separately for each variable to test for significant differences among the four selected clusters in each variable with the significance level fixed at $p<0.001$.

\section{Results}

Italy underwent a progressive development process along the last century as testified by the time trend of the 58 variables considered in this study. Figure 1 illustrates an exploratory PCA carried out separately on the five indicators' themes to illustrate the main time trends in the country. The PCA applied to the seven environmental indicators extracted two components with cumulated variance higher than 85\%. Component 1 (explaining the $63 \%$ of the total variance) is positively associated with urbanization rate, the percentage of both protected areas and forest land on total country surface and indicates a modernization trend towards a more densely populated and urbanized and a less rural country but, at the same time, with more forests, parks and possibly natural areas. This impacts negatively on agricultural areas that declined progressively in the last century. Interestingly, population growth rate is negatively associated to this axis suggesting a non-linear trend over the study period, possibly associated to specific time intervals (e.g. the population boom especially observed after World War II up to the 1970s). The density of the railway network is mostly associated to component 2 (explaining the $23 \%$ of the total variance) possibly indicating a technological axis evolving through the whole modernization period but with a peculiar time trend based on distinct development waves (e.g. in the first decade of the 20th century and in the years immediately after World War II).

The PCA applied to demographic indicators extracts the $82 \%$ of the total variance on the first two axes.

Component 1 correlated with demographic structure variables such as birth and death rates as well as the age structure of the population. This axis well describes the demographic transition in Italy. The second axis is primarily linked to demographic dynamics and functional/social variables, including the migration rate, the marriage rate, the average age at marriage and the rate of natural children and can be considered as a reliable description of the modernization trend in Italy reflected on socio-demographic variables. The PCA applied on education variables extracts the $77 \%$ of the total variance on the first two components. Component 1 identifies an axis characterized by the increase in graduated people (both secondary and tertiary level) and by the opposition between the number of students enrolled in economic faculties (increasing in the most recent decades) and those enrolled in law and medicine faculties (predominant in the early decades of the 20th century). As a proxy of modernization, component 2 was exclusively associated to the percentage of students enrolled in science faculties, showing a peculiar trend over time and mainly increasing in the middle of the studied period, during (or after) events such as wars.

The PCA applied on trade variables reveals a specific modernization pattern illustrated by the first two axes explaining the $67 \%$ of the total variance and mainly based on the increase of both import from and export to North America, primarily United States of America, and the consequent decline of import and export trade from and to Europe. Component 2 well highlights another element of modernization, i.e. the increased dependence on oil against carbon for satisfying the energy demand at the country scale. Finally, the PCA applied to agricultural variables reveals a more complex pattern extracting the $74 \%$ of the total variance and illustrating the opposition between crop with increasing production (BAR, MAI, TOB, together with EGG and PIG) and more traditional crop with decreasing production (BRO, RYE, ALM, HOR) along the first component. The second component better highlights time patterns especially linked with the production of crop concentrated in specific areas of the country such as ALM and OAT. 

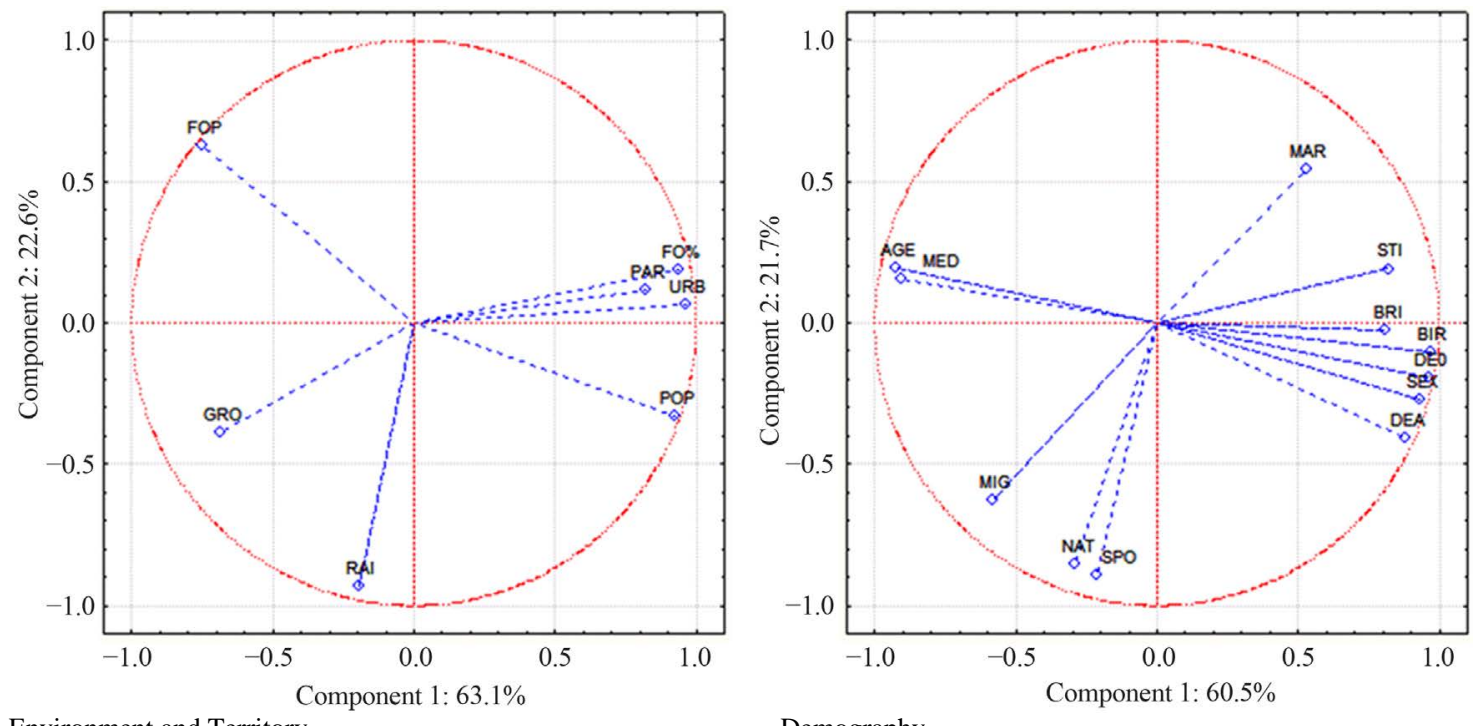

Environment and Territory

Demography
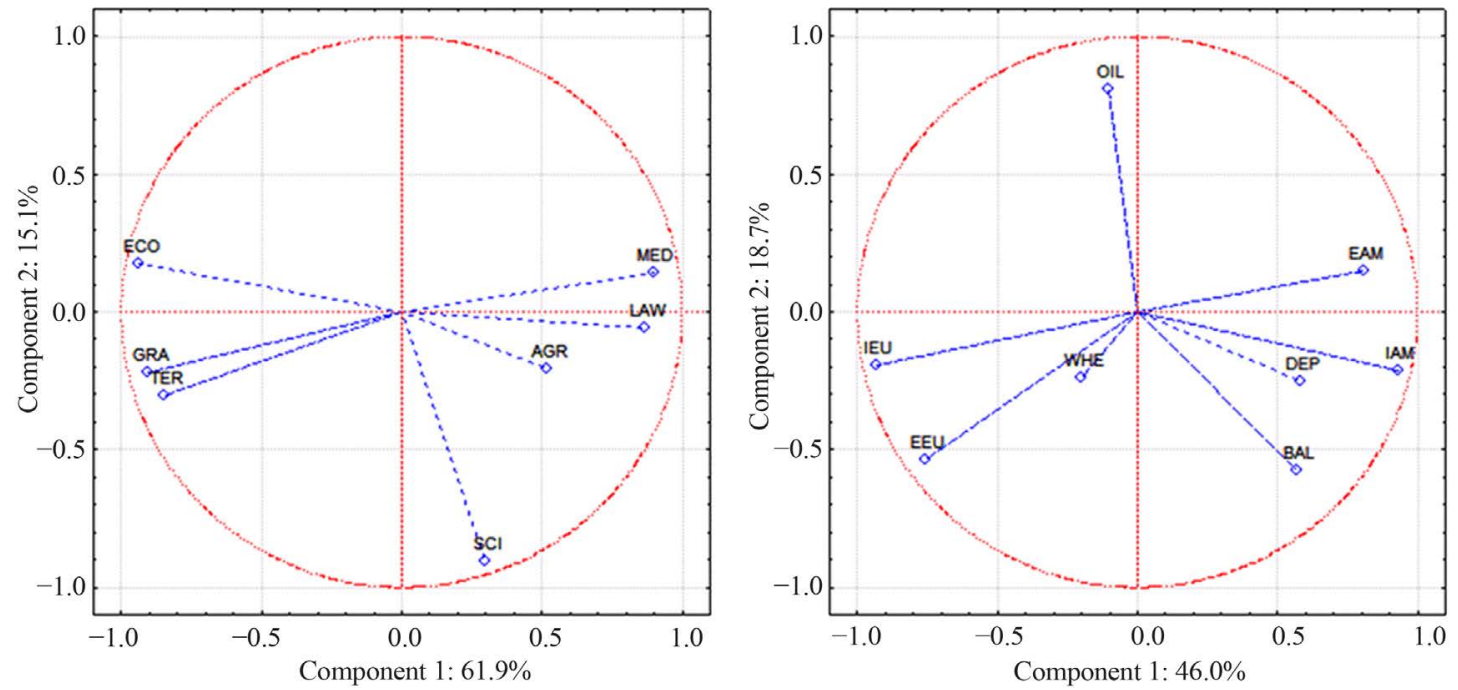

Education Trade

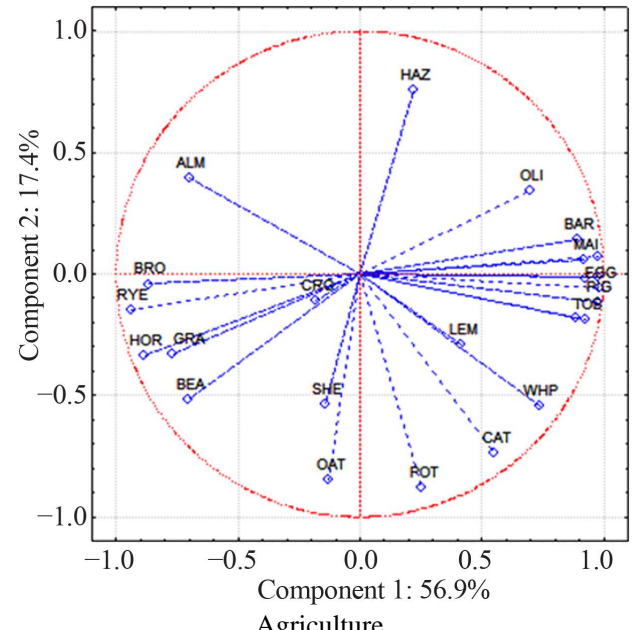

Agriculture

Figure 1. Principal component analysis loading plots by theme. 
Based on hierarchical clustering, the dendrogram reported in Figure 2 classified the 58 indicators in two homogeneous groups using a $70 \%$ similarity threshold based on their time pattern along the period investigated. The left cluster includes 31 variables with a non-linear trend, alternating periods of growth to time intervals with a (less or more) rapid decline and being strongly influenced by the two major wars (1914-1918 and 1940-1945). By contrast, the right cluster includes 27 variables with a linear and continuous time pattern. These variables can be considered as reliable candidates for indicators of modernization, demographic transition and environmental (forest) transition. Modernization indicators include demographic, environmental, education and trade variables together with a major proportion of agricultural variables.

Based on the Cubic Clustering Criterion, four clusters are identified as the best partition for the 147 years belonging to the investigated time series according to the 58 variables collected in our study. Based on non-hierarchical, k-means cluster analysis the studied years were partitioned as follows: cluster 1 (1862-1899), cluster 2 (1900-1930), cluster 3 (1931-1970) and cluster 4 (1971-2009). This classification proved to be homogeneous in terms of cluster size and geometrical distance among clusters (Table 2) well reflecting the time structure of the collected variables. The four groups of years identified may indicate consecutive waves of modernization, based on specific demographic and territorial profiles and correlated with the evolving socioeconomic context.

The most ancient period (1862-1899) was characterized by the highest FOP values (more than one standard deviation above the time-series average), the lowest population density, specific values of demographic variables such as SEX, BIR and DEA as well as the dominance of specific crop production (Table 3). The period

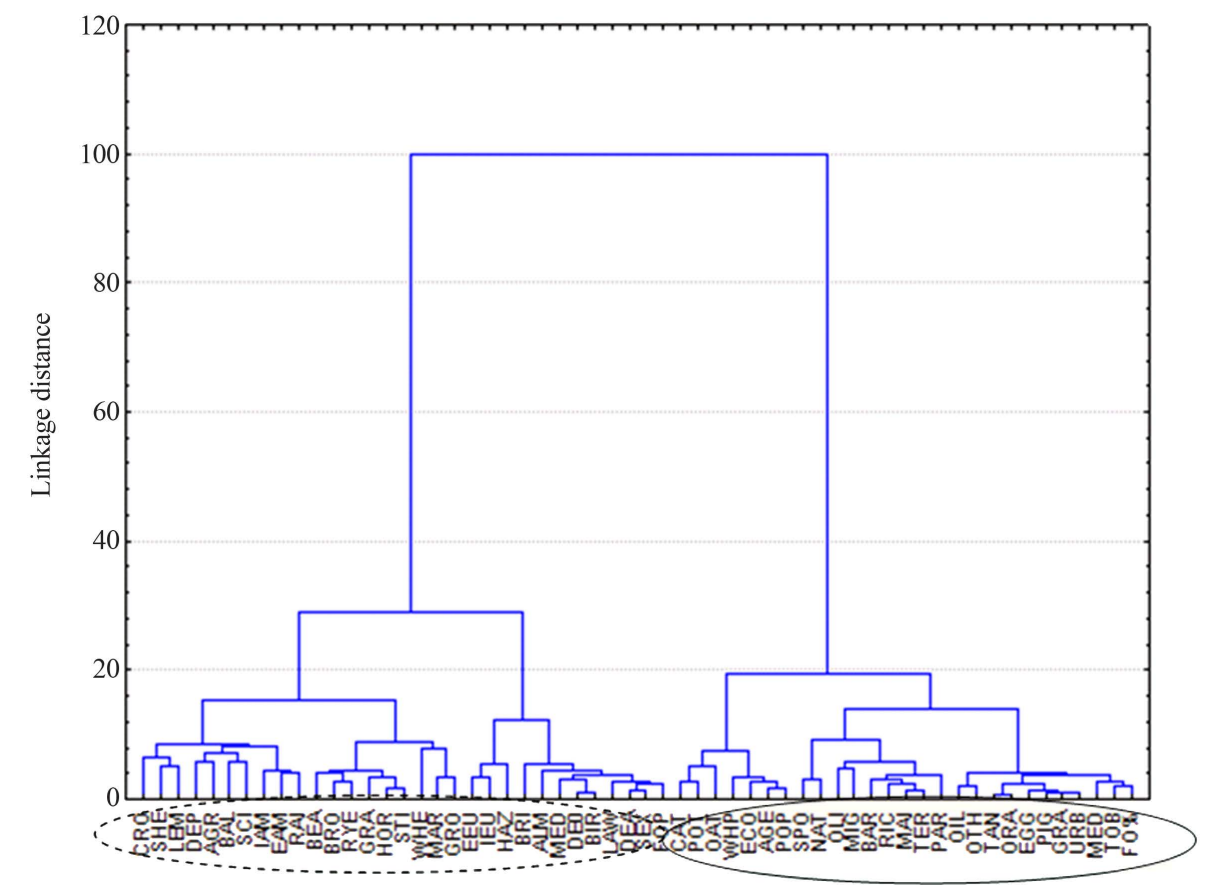

Figure 2. Hierarchical clustering among variables (dotted line indicates the variables showing a non-linear time pattern along the study period compared with the filled line including all variables with a linear time pattern).

Table 2. Euclidean distance matrix among the four k-means clusters.

\begin{tabular}{ccccc}
\hline Cluster & 4 & 3 & 2 & 1 \\
\hline 4 & 0.00 & 1.44 & 2.82 & 3.22 \\
3 & 1.20 & 0.00 & 0.68 & 1.46 \\
2 & 1.68 & 0.82 & 0.00 & 0.87 \\
1 & 1.80 & 1.21 & 0.93 & 0.00 \\
\hline
\end{tabular}


Table 3. Results of the k-means clustering (Fisher-Snedecor F test with 3 and 144 degrees of freedom testing for significant differences among the average standardized value of each cluster by variable).

\begin{tabular}{|c|c|c|c|c|c|}
\hline \multirow{3}{*}{ Variable } & \multicolumn{4}{|c|}{ Standardized value by cluster } & \multirow{3}{*}{$\begin{array}{c}\text { Fisher-Snedecol } \\
\text { F }\end{array}$} \\
\hline & 1 & 2 & 3 & 4 & \\
\hline & 1862-1899 & $1900-1930$ & 1931-1970 & 1971-2009 & \\
\hline $\mathrm{FO} \%$ & -0.76 & -0.83 & -0.04 & 1.44 & 259 \\
\hline FOP & 1.47 & 0.08 & -0.65 & -0.83 & 285 \\
\hline GRO & 0.36 & 0.46 & 0.39 & -1.12 & 39 \\
\hline POP & -1.33 & -0.47 & 0.47 & 1.20 & 817 \\
\hline PAR & -0.65 & -0.59 & -0.01 & 1.11 & 50 \\
\hline RAI & -0.80 & 1.09 & 0.51 & -0.61 & 68 \\
\hline URB & -0.84 & -0.74 & -0.09 & 1.51 & 444 \\
\hline SEX & 1.34 & 0.51 & -0.64 & -1.06 & 628 \\
\hline BIR & 1.26 & 0.53 & -0.36 & -1.27 & 682 \\
\hline DEA & 1.38 & 0.39 & -0.70 & -0.94 & 397 \\
\hline MIG & -0.33 & -0.50 & -0.21 & 0.93 & 23 \\
\hline NAT & 0.24 & -0.23 & -0.71 & 0.67 & 19 \\
\hline STI & 0.39 & 1.16 & 0.12 & -1.43 & 313 \\
\hline BRI & 1.02 & 0.10 & 0.18 & -1.26 & 111 \\
\hline MAR & 0.30 & 0.31 & 0.38 & -0.93 & 22 \\
\hline SPO & 0.24 & -0.25 & -0.40 & 0.38 & 6 \\
\hline AGE & -1.32 & -0.29 & 0.39 & 1.12 & 262 \\
\hline MED & -0.97 & -0.80 & 0.32 & 1.26 & 228 \\
\hline DE0 & 1.23 & 0.61 & -0.43 & -1.25 & 720 \\
\hline TER & -0.72 & -0.67 & -0.31 & 1.55 & 386 \\
\hline GRA & -0.88 & -0.74 & -0.05 & 1.50 & 552 \\
\hline SCI & 0.29 & 0.73 & -0.77 & -0.07 & 20 \\
\hline MED & 1.33 & 0.24 & -0.53 & -0.95 & 175 \\
\hline AGR & 0.02 & 1.11 & -0.50 & -0.39 & 28 \\
\hline ECO & -1.27 & -0.49 & 0.70 & 0.91 & 216 \\
\hline LAW & 1.17 & 0.59 & -0.74 & -0.85 & 159 \\
\hline WHP & -1.18 & -0.61 & 0.68 & 0.93 & 191 \\
\hline RYE & 0.54 & 0.89 & 0.24 & -1.48 & 251 \\
\hline BAR & -0.53 & -0.59 & -0.50 & 1.50 & 202 \\
\hline OAT & -0.97 & 0.54 & 0.92 & -0.42 & 66 \\
\hline RIC & -1.01 & -0.39 & -0.08 & 1.38 & 194 \\
\hline MAI & -0.72 & -0.54 & -0.34 & 1.48 & 198 \\
\hline
\end{tabular}




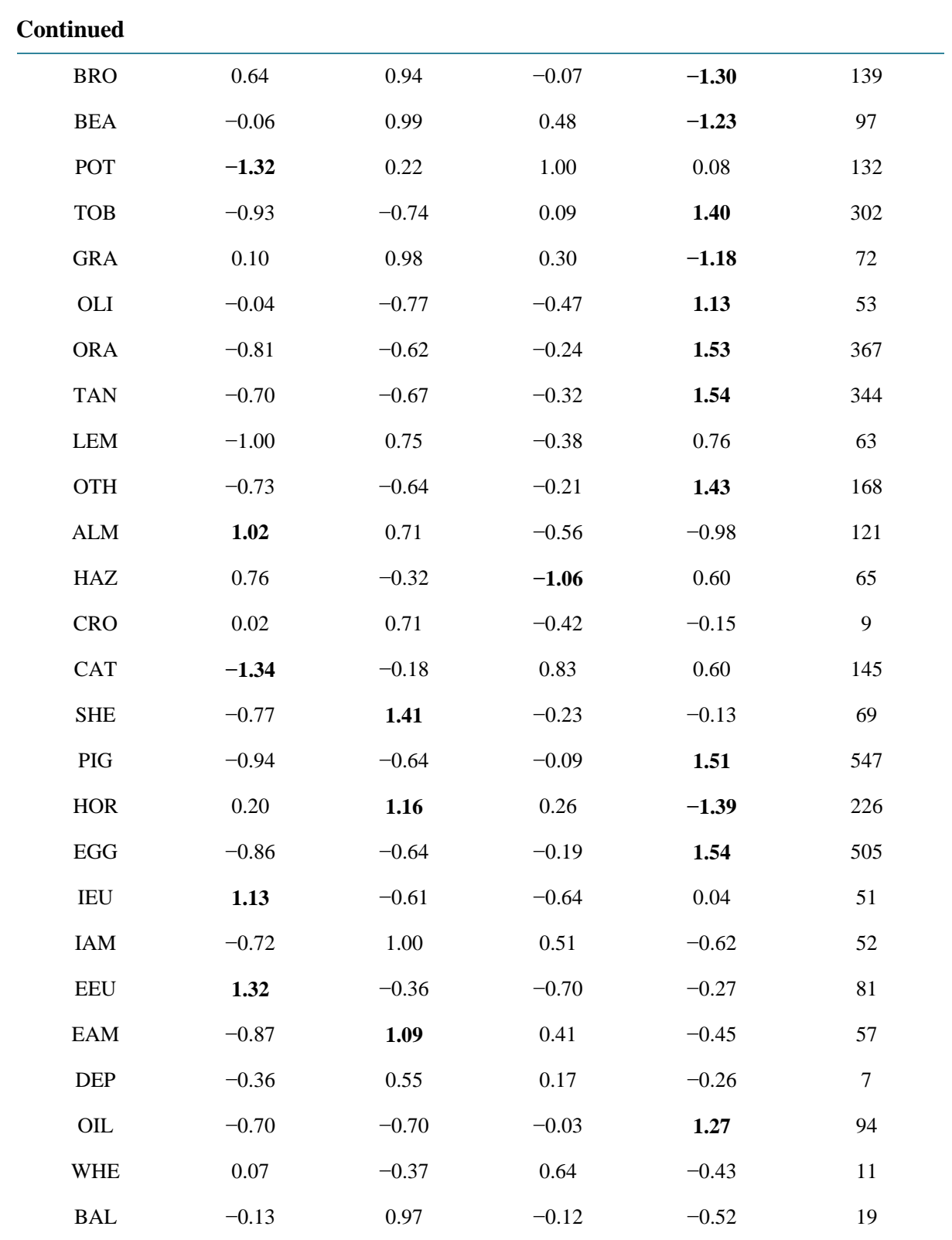

encompassing the First World War (1900-1930) was characterized by a rapid increase in agricultural production, a coherent increase in still birth rate, the highest value for sheep and goats density and the increase in export to north America. This picture indicates a country in a slow transition with marked rural conditions but showing also some signals towards demographic evolution. The period encompassing the Second World War and the "baby boom" (1931-1970) is a period of more rapid transition towards modernization, with no specific indicators showing the highest value along the time series, thus indicating a more or less rapid evolution for all variables considered in our study. The more recent period (1971-2009) is the last step of the modernization transition, showing e.g. the highest energetic dependency on oil, the largest observed production for industrial crop, the highest number of graduated students, the highest urbanization rate together with the highest forest cover rate, supported also by the highest increase in protected natural areas. Based on the Fisher-Snedecor test, the variables with the most rapid dynamic along the four time periods are population density, sex ratio, birth rate, the rate of children died at age 0 - 4 years, the percentage of graduated students together with pig production. These variables can be considered as particularly suited to represent the different modernization phases occurred in Italy in the last 150 years. 


\section{Discussion and Conclusions}

Modernization was considered as the process of change towards those types of social, economic and political systems that have developed in Western Europe and North America from the seventeenth century to the nineteenth and have then spread to other countries [1]-[3]. Modernization theory has been one of the major perspectives in the understanding of developing trends and pattern at country and regional scale since the 1950s with a special focus on past and present pre-modern societies and their transition to a Westernized pattern through processes of economic growth and changes in social, political and cultural structures. The specific interest of the present study is to provide an overview of the Italian transition towards modernization with a special focus on environmental (mainly forest) variables and a continuous link with the demographic transition following the main changes in the economic structure. The original contribution of this study is in the use of a wide set of variables analyzing jointly environmental, demographic, social and economic trends over an enough long time period (150 years) on the annual base. A data mining approach provided a comprehensive interpretation for this heterogeneous data sample by identifying variables with comparable time patterns and grouping years into few homogeneous groups with a specific socioeconomic profile characterizing different modernization waves in Italy.

Developed countries showed turning points from decline to expansion of forest land generally in the years belonging to a transition period between World War I and the 1950s [24] [26] [27]. This period coincided with rapid demographic changes as our analysis clearly points out [12] confirming the relationship existing between demographic and environmental transitions in developed country, as hypothesized in this study. This transition is based on a rapidly changing socioeconomic context. The results of this study also confirm previous analyses indicating the decrease (and the subsequent increase) in forest area being associated with a large spectrum of socioeconomic processes driven by industrialization, urbanization and rapid changes in agricultural systems towards crop intensification [32]. By contrast, highly variable patterns accompanied environmental variables at the national scale possibly indicating the positive correlation between urbanization and forestation but also more specific dynamics at the local scale [8]. Interestingly, the cluster analysis identifies four homogeneous periods in the time series considered as progressive waves of modernization in Italy with specific socioeconomic, demographic and environmental profiles [11]. This represents an original contribution to the modernization theory in association with the demographic transition theory and the forest transition theory.

The increased environmental awareness together with an expanded network of protected areas, in turn associated to depopulation and land abandonment in disadvantaged, internal areas are primary drivers for the increase in forest cover. Demographic dynamics in urban and peri-urban areas indirectly influence this process by polarizing population density and relegating large portions of the national territory to marginal economic conditions and unbalanced demographic structures with stagnant population dynamics. Our results finally highlight the importance of integrated assessment frameworks evaluating jointly environmental and socio-demographic issues in the light of the modernization theory.

\section{References}

[1] Lerner, D. (1958) The Passing of Traditional Society: Modernizing the Middle East. The Free Press, Glencoe.

[2] Harrison, D. (1988) The Sociology of Modernization and Development. Unwin Hyman, London. http://dx.doi.org/10.4324/9780203359587

[3] Levy Jr., M. (1966) Modernization and the Structures of Societies. Princeton University Press, Princeton.

[4] Khan, J.S. (2001) Modernity and Exclusion. Sage, London. http://dx.doi.org/10.4135/9781446279038

[5] Giddens, A. (1991) Modernity and Self-Identity; Self and Society in the Late Modern Age. Polity Press, Cambridge.

[6] Inglehart, R. and Welzel, C. (2005) Modernization, Cultural Change and Democracy: The Human Development Sequence. Cambridge University Press, New York.

[7] Parsons, T. (1951) The Social System. Free Press, New York.

[8] Harte, J. (2007) Human Population as a Dynamic Factor in Environmental Degradation. Population and Environment, 28, 223-236. http://dx.doi.org/10.1007/s11111-007-0048-3

[9] Chesnais, J.-C. (1993) The Demographic Transition: Stages, Patterns, and Economic Implications: A Longitudinal Study of Sixty-Seven Countries Covering the Period 1720-1984. Oxford University Press, Oxford, 633 p.

[10] Dudley, K. (1996) The Demographic Transition. Population Studies, 50, 361-387. 
http://dx.doi.org/10.1080/0032472031000149536

[11] Myrskyla, M., Kohler, H.-P. and Billari, F. (2009) Advances in Development Reverse Fertility Declines. Nature, 460, 741-743. http://dx.doi.org/10.1038/nature08230

[12] Baudelle, G. and Olivier, D. (2006) Changement Global, Mondialisation et Modèle De Transition Démographique: Réflexion sur une exception française parmi les pays développés. Historiens et Géographes, 98, 177-204. (In French)

[13] Mather, A.S. (1992) The Forest Transition. Area, 24, 367-379. http://www.jstor.org/stable/20003181

[14] Mather, A.S., Needle, C. and Coull, J. (1998) From Resource Crisis to Sustainability: The Forest Transition in Denmark. International Journal of Sustainable Development and World Ecology, 5, 183-192.

[15] Rudel, T.K. (2009) Tree Farms: Driving Forces and Regional Patterns in the Global Expansion of Forest Plantations. Land Use Policy, 26, 545-550. http://dx.doi.org/10.1016/j.landusepol.2008.08.003

[16] Redo, D.J., Graub, H.R., Aidea, T.M. and Clark, M.L. (2012) Asymmetric Forest Transition Driven by the Interaction of Socio-Economic Development and Environmental Heterogeneity in Central America. Proceedings of the National Academy of Sciences of the United States of America, 109, 8839-8844. http://dx.doi.org/10.1073/pnas.1201664109

[17] Mather, A.S. (2004) Forest Transition Theory and the Reforesting of Scotland. Scottish Geographical Journal, 120, 83-98. http://dx.doi.org/10.1080/00369220418737194

[18] Mather, A.S. (2007) Recent Asian Forest Transitions in Relation to Forest-Transition Theory. International Forestry Review, 9, 491-502. http://dx.doi.org/10.1505/ifor.9.1.491

[19] Gutiérrez Rodríguez, L. and Ruiz Pérez, M. (2013) Recent Changes in Chinese Forestry Seen through the Lens of Forest Transition Theory. International Forestry Review, 15, 456-470. http://dx.doi.org/10.1505/146554813809025711

[20] He, J., Lang, R. and Xu, J. (2014) Local Dynamics Driving Forest Transition: Insights from Upland Villages in Southwest China. Forests, 5, 214-233. http://dx.doi.org/10.3390/f5020214

[21] Yackulic, C.B., Fagan, M., Jain, M., Jina, A., Lim, Y., Marlier, M., Muscarella, R., Adame, P., DeFries, R. and Uriarte, M. (2011) Biophysical and Socio-Economic Factors Associated with Forest Transitions at Multiple Spatial and Temporal Scales. Ecology and Society, 16, 15.

[22] DeFries, R.S. and Pandey, D. (2010) Urbanization, the Energy Ladder and Forest Transitions in India's Emerging Economy. Land Use Policy, 27, 130-138. http://dx.doi.org/10.1016/j.landusepol.2009.07.003

[23] Meyfroidt, P. and Lambin, E.F. (2008) The Causes of the Reforestation in Vietnam. Land Use Policy, 25, $182-197$. http://dx.doi.org/10.1016/j.landusepol.2007.06.001

[24] Klooster, D. (2003) Forest Transitions in Mexico: Institutions and Forests in a Globalized Countryside. The Professional Geographer, 55, 227-237.

[25] Hecht, S.B., Kandel, S., Gomes, I., Cuellar, N. and Rosa, H. (2006) Globalization, Forest Resurgence, and Environmental Politics in El Salvador. World Development, 34, 308-323. http://dx.doi.org/10.1016/j.worlddev.2005.09.005

[26] Bray, D.B. and Klepeis, P. (2005) Deforestation, Forest Transitions, and Institutions for Sustainability in Southeastern Mexico, 1900-2000. Environment and History, 11, 195-223. http://dx.doi.org/10.3197/0967340057744434584

[27] Rudel, T.K., Bates, D. and Machinguiashi, R. (2002) A Tropical Forest Transition? Agricultural Change, Out-Migration, and Secondary Forests in the Ecuadorian Amazon. Annals of the Association of American Geographers, 92, 87102. http://dx.doi.org/10.1111/1467-8306.00281

[28] de Jong, W. (2009) Forest Rehabilitation and Its Implication for Forest Transition Theory. Biotropica, 42, 3-9. http://dx.doi.org/10.1111/j.1744-7429.2009.00568.x

[29] Barbier, E.B., Burgess, J.C. and Grainger, A. (2009) The Forest Transition: Towards a More Comprehensive Theoretical Framework. Land Use Policy, 27, 98-107. http://dx.doi.org/10.1016/j.landusepol.2009.02.001

[30] Pagnutti, C., Bauch, C.T. and Anand, M. (2013) Outlook on a Worldwide Forest Transition. PLoS ONE, 8, e75890. http://dx.doi.org/10.1371/journal.pone.0075890

[31] Rudel, T.K. (2009) Tree Farms: Driving Forces and Regional Patterns in the Global Expansion of Forest Plantations. Land Use Policy, 26, 545-550. http://dx.doi.org/10.1016/j.landusepol.2008.08.003

[32] Meyfroidt, P. and Lambin, E.F. (2011) Global Forest Transition: Prospects for an End to Deforestation. Annual Review of Environment and Resources, 36, 343-371. http://dx.doi.org/10.1146/annurev-environ-090710-143732

[33] Bajocco, S., De Angelis, A., Perini, L., Ferrara, A. and Salvati, L. (2012) The Impact of Land Use/Land Cover Changes on Land Degradation Dynamics: A Mediterranean Perspective. Environmental Management, 49, 980-989. http://dx.doi.org/10.1007/s00267-012-9831-8

[34] Salvati, L., De Angelis, A., Bajocco, S., Ferrara, A. and Barone, P.M. (2013) Desertification Risk, Long-Term LandUse Changes and Environmental Resilience: A Case Study in Basilicata, Italy. Scottish Geographical Journal, 129, 85-99. http://dx.doi.org/10.1080/14702541.2013.781209 
[35] Ferrara, A., Salvati, L., Sabbi, A. and Colantoni, A. (2014) Soil Resources, Land Cover Changes and Rural Areas: Towards a Spatial Mismatch? Science of the Total Environment, 478, 116-122.

http://dx.doi.org/10.1016/j.scitotenv.2014.01.040

[36] Istat (2006) Atlante statistico dei comuni. Istituto Nazionale di Statistica, Roma. 
Scientific Research Publishing (SCIRP) is one of the largest Open Access journal publishers. It is currently publishing more than 200 open access, online, peer-reviewed journals covering a wide range of academic disciplines. SCIRP serves the worldwide academic communities and contributes to the progress and application of science with its publication.

Other selected journals from SCIRP are listed as below. Submit your manuscript to us via either submit@scirp.org or Online Submission Portal.
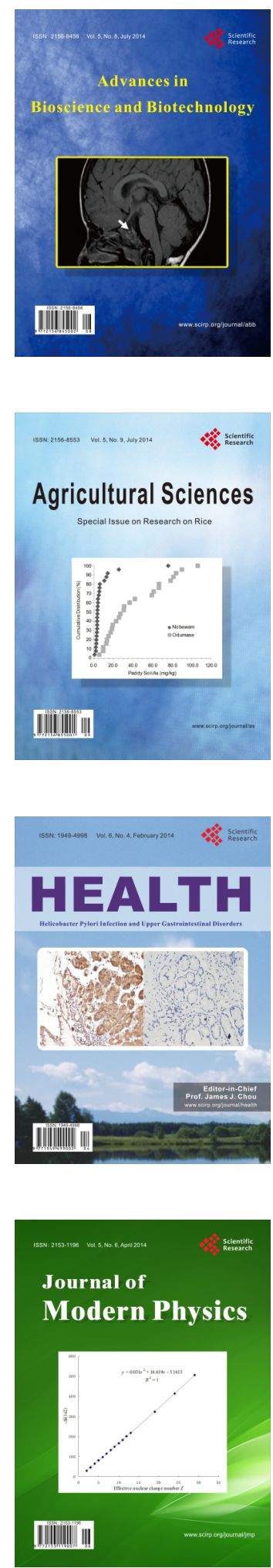
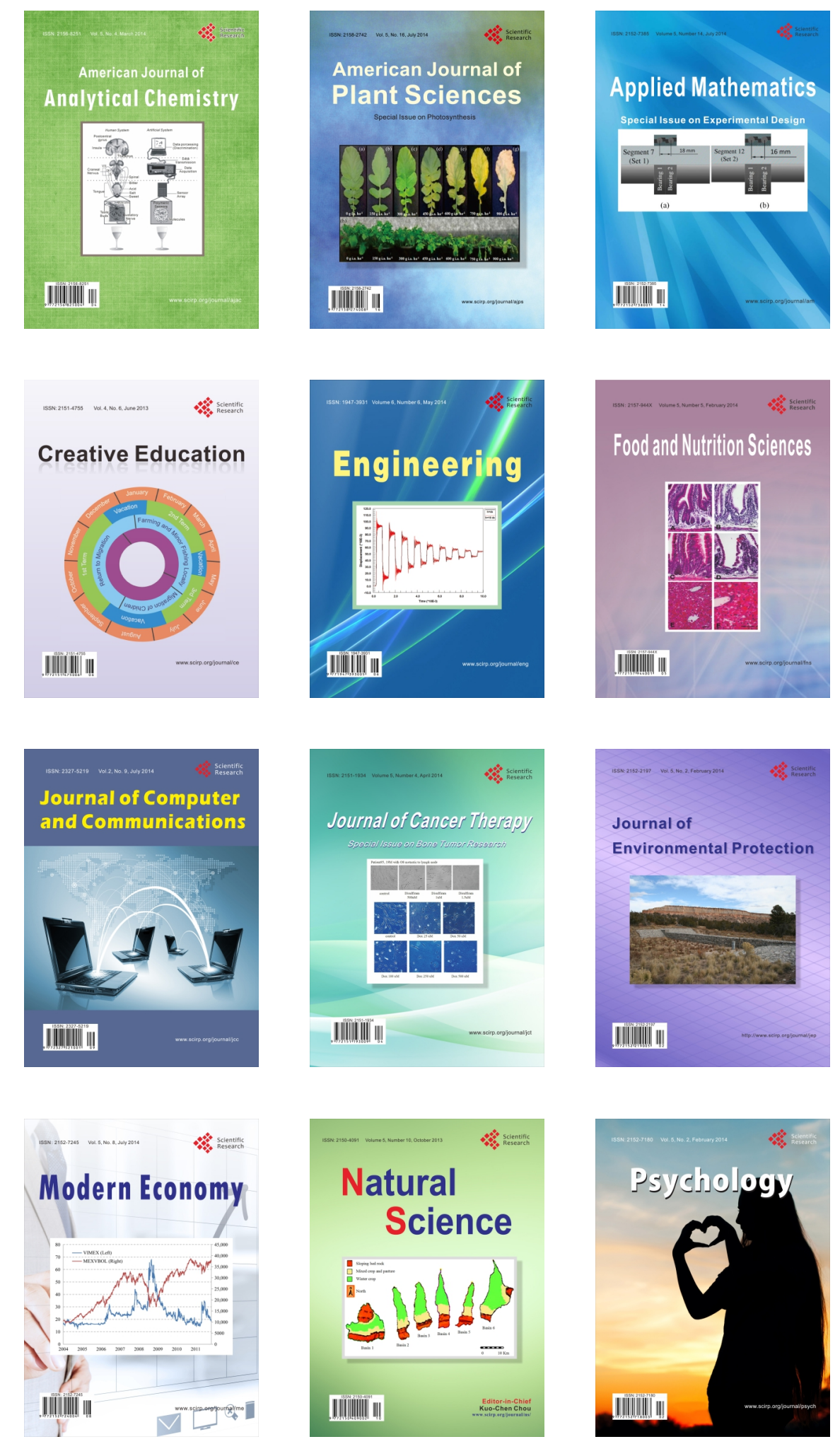